\title{
Craniosacral Therapy
}

\author{
Małgorzata Wójcik* \\ Department of Public Health, Stanisław Staszic University of Applied Sciences in Piła, Poland
}

*Corresponding author: Małgorzata Wójcik, Department of Public Health, Stanisław Staszic University of Applied Sciences in

Piła, Poland

\begin{tabular}{|c|c|}
\hline ARTICLE INFO & ABSTRACT \\
\hline 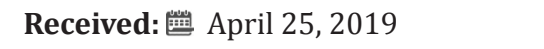 & \multirow{3}{*}{$\begin{array}{l}\text { Craniosacral therapy is a therapy for the whole body, it has a very wide impact on } \\
\text { human health. The therapist working with craniosacral therapy has to use a very delicate } \\
\text { touch, but a very good knowledge of human anatomy is also required. Therapy is effective } \\
\text { in cases of dysfunctions within the area of the cranium and pelvis, disturbed vision and } \\
\text { hearing, sinus pain, hyperactivity, concentration problems, chronic stress, also amongst } \\
\text { dental patients. As every other method, it has contraindications for its use, they include } \\
\text { intracranial bleeding, brain aneurysm, skull injuries, bone fractures and medulla oblongata } \\
\text { herniations. Craniosacral therapy can be combined with other therapeutic approaches. }\end{array}$} \\
\hline Published: 慧 April 29, 2019 & \\
\hline $\begin{array}{l}\text { Citation: Małgorzata Wójcik. Craniosa- } \\
\text { cral Therapy. Biomed J Sci \& Tech Res } \\
\text { 17(4)-2019. BJSTR. MS.ID.003024. }\end{array}$ & \\
\hline
\end{tabular}

\section{Introduction}

The founding of a school of osteopathy in 1892 by Andrew Taylor Still, played a decisive role in the development of modern manual therapy. He specified three main principles that gave rise to osteopathy:

a) Structure and function remain in reciprocal relations,

b) The body functions as a unity in health and illness,

c) The body is a self-healing mechanism [1].

He also recognized the great importance of the free circulation of body fluids (blood, lymph and cerebrospinal fluid) and that it is necessary for the proper functioning of cells and clearing them of toxins [1]. He also observed that the relationship between structure and function is reciprocal. Many well-known osteopaths were educated at the school of osteopathy founded by Still. One of them was William Garner Sutherland, who contributed to the development of cranial therapy in the 1930s. In 1932 he presented his discovery to the American Osteopathic Association, stating that the central nervous system and its associated structures are subject to constant rhythmic movements and that this movement is an important feature for human health and life [2]. The development of craniosacral therapy was influenced by Frymann, Weaver, Cottam, Magoun, DeJarnette, Becker, Fulford, Handy, Arbuckle, Wales, Schooley, Upledger, Mitchell, Chila, Jealous, Blackman, Heede, Abehsera, McPartland and Pick [3]. Currently, craniosacral therapy is widely used in cases of various diseases, and it utilises the following approaches: structural, membranous and fluid fluctuations [1]. It is used in dentistry in patients with degeneration and dysfunctions of the temporomandibular joint, bruxism and with patients using orthodontic splints and braces [3]. Therapy is also used in patients with the following conditions: fibromyalgia, multiple sclerosis, children with cerebral palsy and variety of other disabilities, infant colic, myopia and hyperopia, asthma, migraine [4-8]. A pilot study of Cutler et. al showed that the CV4 technique influences the change in sleep latency [9].

\section{Discussion}

The craniosacral therapists believe that the primary respiratory rhythm is an important element, that includes intrinsic movements of the brain and spinal cord, fluctuation of the cerebrospinal fluid, mobility of the dural membranes and sacrum between the iliac plates [2]. It has been shown that brain movements are synchronous with heart and blood vessel spasms. It has been proven that the dura mater responds to changes in the length of the spine and that there are minimal movements inside the cranial sutures while performing body movements [1]. Based on various measurement methods such as palpation, ultrasound, measurements at the molars, cranial measurements, motion detectors, CT; various values of 2.5 - 14 cycles per minute of the craniosacral rhythm were determined [1,10-12]. Sutherland called this rhythm "the breath of life" [1]. He observed that regular pulsation of the cerebrospinal fluid affects the movements of the skull and sacral bones being a response to the pulsation of cerebrospinal fluid. 
The fluid goes to the brain in the initial phase and then in the next, it goes to the sacrum. The fluctuation of cerebrospinal fluid "cleans" the roots of the brainstem, which belongs to the autonomic nervous system. In turn, this area controls the centre of respiration and circulation, the centre responsible for metabolism and reticular formation [1]. Sutherland mentioned five basic components of the craniosacral system: the congenital fluctuation of the cerebrospinal fluid, mobility of the central nervous system, mutual tension of the meninges, mobility of the skull bones at the seams and the movement of the sacral bone [1]. Congenital cerebrospinal fluid fluctuation is also called pulsation, which occurs in the meninges and spinal cord [1]. The fluid is a colourless liquid that fills the subarachnoid space of the brain, its ventricles and the spinal cord. Its function is to provide cushioning for the central nervous system when sudden changes in position occur as well as in the case of injuries. Another function of the fluid is rinsing the central nervous system from metabolic toxins and compensating for changes in the pressure inside the skull [13].

The fluid fills the subarachnoid space between the dura mater and the pia mater, thus protecting the brain and the core [13]. It is produced by choroid plexuses in the cerebral ventricles, from where it enters the third ventricle and the aqueduct of Sylvius to the fourth ventricle and there it flows into the subarachnoid space of the spinal cord [13]. When considering the mutual tension of the dural system, first of all, one needs to take into account the anatomical relationships. As the outermost structure, the dura mater covers the brain and spinal cord, its outer lamina inside the skull fuses with the bones forming periosteum, which explains the fact that the craniosacral system is connected to the dura $[1,13]$. Sutherland was the first to observe that the dura mater is in tension, which is variable and mobile, corresponding to the pulsation of the cerebrospinal fluid and the mobility of the central nervous system [1]. The tension of the dura mater is manifested within the skull through folds made up of double durability, dividing the brain space into the sickle of the brain and the sickle and tent of the cerebellum $[13,14]$. The tension in the dura mater also concentrates at the front end of the straight sinus, where there is a connection to the vena cerebri magna [1].

The straight sinus is located at the connection of the falx cerebri with the two wings of the cerebellum $[1,13]$. The position of the straight sinus may change under the influence of a trauma (mechanical, emotional) manifesting in the tensions in the dura mater [1]. The dura mater is innervated by the following nerves: trigeminal, laryngopharyngeal, vagus, dural branches of the ophthalmic nerve, maxillary [13]. Bearing in mind the innervation, one should take into account the possibility of pain projected in the situation of restriction of these nerves. There may be a pain: homolaterally behind the eye, in the area of the face and parietal bones, behind the ear, at the occiput and the neck [1]. Another important element of craniosacral therapy is the restoration of normal skull bone mobility, which is formed by twenty-two bones. Six of them are in the mid-line and they are odd bones, eight even bones are located on the both sides (paired bones) [13]. Individual (odd) bones are connected with the following sutures: coronal, sagittal, lambdoid, occipitomastoid, parietomastoid, frontoparietal, temporozygomatic, temporomandibular, frontonasal, frontomaxillary, frontolacrimal, nasomaxillary, lacrimomaxillary, zygomaticomaxillary [13].

The lambdoid suture is a suture that ossifies as the last, this process occurs around the age of fifty [1]. The function of sutures is to provide minimal mobility, the ability of growth of the skull, they connect the skull bones, allowing the passage through the birth canal, provide resistance and protection against mechanical factors, i.e. impacts, falls, compression by absorbing kinetic force [14-18]. The mobility of the skull bones has been a subject of much research. Sutherland observed that the bones of the skull are connected in such a way that allows for their slight movements, calling the sphenoid bone "the main cogwheel" of the cranial-sacral system, around which the movement takes place. The bone is anatomically located in such a place that all structures surround it $[1,13]$. When defining the movement of paired structures, the term external and internal rotation is used, flexion and extension refer to the movement of individual structures [18]. The assessment of bone mobility is a very important element of craniosacral therapy [13]. Upledger and his team of researchers were the first to confirm the presence of connective tissue, blood vessels and nerves in the sutures, thus proving that the bones of the skull of an adult human are not connected into one fixed entity $[13,18]$.

Based on the conducted studies, it has been proven that the complete ossification of the sphenobasilar synchondrosis occurs between 16 and 18 years of age [1]. When carrying out the therapy of skull bones one should remember about twelve pairs of cranial nerves, coming from the lower part of the brain [13]. The emerging restrictions located in the bones, tissues and cranial membranes can lead to hypersensitivity of the cranial nerves. Common tinnitus and hearing disorders may result from irritation of the vestibulocochlear nerve which supplies the ear $[1,13]$. The nerves that pass through jugular foramen are the laryngopharyngeal nerve, vagus nerve and accessory nerve, if they become hypersensitive due to restriction, the symptoms may be very extensive (migraine headaches, arrhythmias, breathing and sleep disorders) [1]. Often, irritation of the vagus nerve is the cause of colic in young children [1]. The last element of the craniosacral system is the involuntary movement of the sacrum. The dura mater connects to the sacrum at the level of the other vertebra, thus giving the connection to the central nervous system [13]. During the cranial inspiration during the ascent of the cerebrospinal fluid into the skull, the dura mater rises, thereby pulling the sacrum which is vertically aligned [1].

During the cranial exhalation, the opposite process takes place - the sacral bone sets itself horizontally [1]. The bone also has its own mobility, during the cranial inhalation, flattening and widening takes place, with the cranial exhalation, the bone narrows, the 
base and the apex move towards the front [1]. The sacrum plays an important role in the craniosacral system $[1,13]$. Parietal and temporal bones function interdependently with the pelvic bones [1]. One of the main principles proclaimed by Andrew Taylor Still is that structure and function remain in mutual influence [1]. Looking at the human body in a holistic way, a significant effect on the craniosacral system is also exerted by the fascia. Many of its functions are attributed to it: it is responsible for stabilization and protection, it divides the human body into individual parts, merges muscles, vessels, nerves and internal organs into a whole, thus giving the body shape. By giving the shape of the body the fascia is responsible for the posture of the body. It is the sender, receiver and regulator of the tension in the body. The fascia is attributed to the effects on the flow of body fluids. Its dysfunction affects the lymph circulation at the cellular level, which translates into the functioning of the body's immune system. It has a constant ability to absorb/dampen the forces influencing the human body.

\section{Conclusion}

Craniosacral therapy is currently widely used, but one should pay special attention to the anatomy and physiology of structures that undergo this therapy.

\section{References}

1. Liem T (2009) Cranial Osteopathy. Eastland Press p. 1-13.

2. Handy CL (1948) History of Cranial Osteopathy. JAOA 47(1): 269-272.

3. Andersen T, Bahr Ch, Ciranna-Raab C (2013) Efficacy of osteopathy and other manual treatment approaches for malocclusion - a systematic review of evidence. IJOM 16(2): 99-113.

4. Jäkel A, Von Hauenschild P (2011) Therapeutic effects of cranial osteopathic manipulative medicine: a system review. JAOA 111(12): 685-693.

5. Jäkel A, von Hauenschild P (2012) A systematic review to evaluate the clinical benefits of craniosacral therapy. Comp Ther in Med 20: 456-465.

ISSN: 2574-1241

DOI: 10.26717/BJSTR.2019.17.003024

Małgorzata Wójcik. Biomed J Sci \& Tech Res

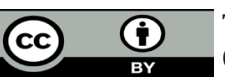

This work is licensed under Creative Commons Attribution 4.0 License

Submission Link: https://biomedres.us/submit-manuscript.php
6. Mehl-Madrona L, Kliger S, Silverman S, Lynthon H, Merrel W (2007) The impact of acupuncture and craniosacral therapy interventions on clinical outcomes in adults with asthma. Explore 3(1): 28-36.

7. Mann JD, Keturah RF, Wilkinson L, Curtis P, Coeytaux RR, Suchindran C, Gaylors SA et al. (2008) Craniosacral therapy for migraine: protocol development for an exploratory controlled clinical trial. Comp Ther in Med 8: 28.

8. Arnadottir TS, Sigurdardottir AK (2013) Is craniosacral therapy effective for migraine? Tested with HIT-6 questionnaire. Comp Ther in Med 19: $11-14$.

9. Cutler MJ, Holland BS, Stupski BA, Gamber RG, Smith ML (2005) Cranial manipulation can alter sleep latency and sympathetic nerve activity in humans: a pilot study. J Altern Complement Med 11(1): 103-108.

10. Wirth Patullo V, Hayes KW (1994) Interrater reliability of craniosacral measurments and their relationship with subjets and examiners heart and respiratory Measurments. Phys Ther 74: 908-920.

11. Nelson KE, Segueef N, Lipinski CM, Chapman AR, Glonek T (2001) Cranial rhythmic impulse related to the Traube - Hering - Mayer oscillation laser Doppler flowmetry and palpation. J Am Osteopath. Assoc. 101: 163-173.

12. Liem T (2011) Palpation des kraniosakralen rhythmus. Osteopathie Medizin 4: 12-17.

13. Bochenek A, Reicher M (2016) Anatomia Człowieka. PZWL, tom I p.233236, tom V pp. 161-236.

14. Schünke M, Schulte E, Schumacher U, Voll M, Wesker K (2009) Atlas anatomii człowieka. Głowa i neuroanatomia. MedPhram, p. 2-5,74-77.

15. Liem T (2004) Kraniosacrale Osteopathie Rhytmic Balanced Interchabge, Munchen, video commerz.

16. Meikle MC, Reynolds JJ, Sellers A, Dingle JT (1979) Rabbit cranial sutures in vitro; a new experimental model for studying the response of fibrous joints to mechanical stress. Calcif Tissue Int 28(2): 137-144.

17. Meikle MC, Sellers A, Reynolds JJ (1980) Effect of tensile mechanical stress on the synthesis of metalloproteinases by rabbit coronal sutures in vitro. Calcif Tissue Int 30(1): 77-82.

18. Jaslow CR (1990) Mechanical properietes of cranial sutures. J Biomech 23: $313-321$.

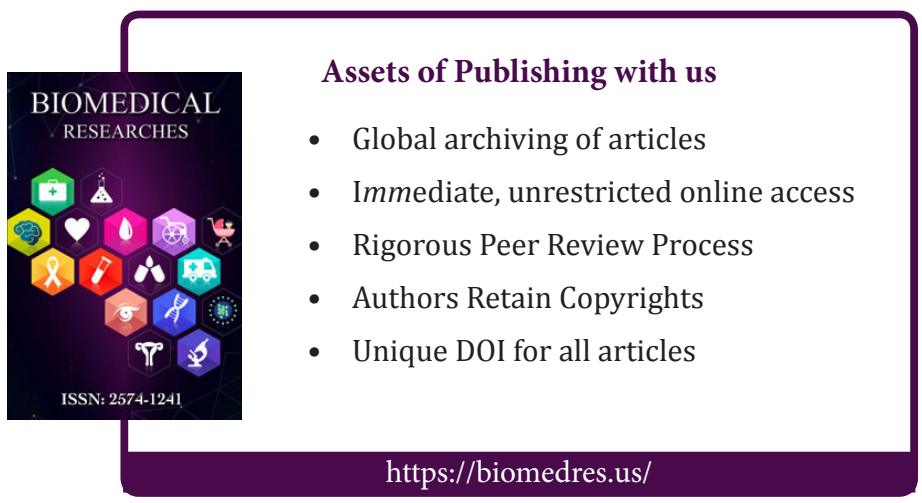

